\title{
Carborane inclusion chemistry for the uncommon calix[7,9]arenes $\dagger$
}

\author{
Received (in XXX, XXX) 1st January 2007, Accepted 1st January 2007 \\ First published on the web 1st January 2007 \\ ${ }_{5}$ DOI: 10.1039/b000000x
}

Thomas E. Clark, Mohamed Makha, Alexandre N. Sobolev and Colin L. Raston*

The inclusion of $o$-carborane by $p$ - $\mathrm{Bu}^{\mathrm{t}}$-calix[7,9]arenes has been investigated by solid state and solution studies, with both resulting complexes in the solid state being rich in carborane with the ratio of calixarene to carborane at 1:7 and 2:7 respectively. The carboranes reside in clefts within the calixarenes which arise from specific local conformations of adjacant phenolic groups, or are

10 included in the extended strucutre through other interplay of the calixarenes and carboranes in such clefts.

\section{Introduction}

Calixarenes are versatile macrocyclic molecules that are prepared by the condensation reaction of $p$-substituted phenols 15 with formaldehyde in the presence of base or acid. The socalled "major" $p$-Bu'-calix[n]arenes, $(\mathrm{n}=4,6,8)$, sythesized by the condensation of $p$-But-phenol can be reproducibily synthesized in good yield and this has led to them being extensively investigated. ${ }^{1}$ In contrast the "minor" $p$ - $\mathrm{Bu}^{\mathrm{t}}$ 20 calix[n]arenes, $(n=5,7)$, are less well investigated mainly due to low yielding synthetic procedures (15-17\%). Nevertheless, recent advances in their synthetic procedures has led to significant developments in the supramolecular chemistry of these compounds. ${ }^{2}$

25 In addition to the "minor" $p$ - $\mathrm{Bu}^{\mathrm{t}}$-calix[n]arenes the "large" $p$-Bu-calix[n]arenes, $(\mathrm{n}=9-20)$, can also be prepared in low yields (8.6-0.2\%), which until now has limited their synthetic usefullness. ${ }^{3}$ A new synthetic protocol for the prepration of $p$ $\mathrm{Bu}^{\mathrm{t}}$-calix[9]arene in $23 \%$ yield has opened up the 30 supramolecular chemistry of the compound. ${ }^{4}$ We note that there has only been three reported structures containing $p$ - $\mathrm{Bu}^{\mathrm{t}}$ calix[9]arene, as its uranium and europium complexes. ${ }^{5}$

We now report the first inclusion complex of $p$ - $\mathrm{Bu}^{\mathrm{t}}-$ calix[9]arene with $o$-carborane, rich in the carborane with 35 overall composition 2(p-But-calix[9]arene).7(ocarborane).2(cyclohexane).5( $\left.\mathrm{H}_{2} \mathrm{O}\right), 1$, Fig. 1, with the $o$ carborane residing in clefts generated by the calix[9]arene molecules forming $\mathrm{C}-\mathrm{H} \cdots \pi$ interactions with the aromatic rings.

40 We also report inclusion complexes of the corresponding calix[7]arene, both the carborane free complex $p$ - $\mathrm{Bu}^{\mathrm{t}}$ calix[7]arene.3\%(toluene), 2 , and the carborane complex which like the above complex for the higher calixarene, is rich in carborane with overall composition $p$ - $\mathrm{Bu}^{\mathrm{t}}$ 45 calix[7]arene.7(o-caborane).2(toluene).2(benzene), 3, Fig. 1. For the other uneven numbered calix[5]arene, the carborane incusion complexes are dominated by 1:1 host-guest molecules with a carborane in the cavity of the calixarene, ${ }^{6}$ interestingly with the $p$-H-calix[5]arene giving a carborane 50 rich complex, as well as a calixarene rich complex. ${ }^{6 a}$ Related to this is the formation of $o$-carborane complexes with cyclotriveratrylene and $p$-benzyl-calix[4]arene which are bowl shaped molecules with complementarity of fit with the globular molecule associated with $\mathrm{C}-\mathrm{H} \cdots \pi$ interactions. $^{7,8}$ 55

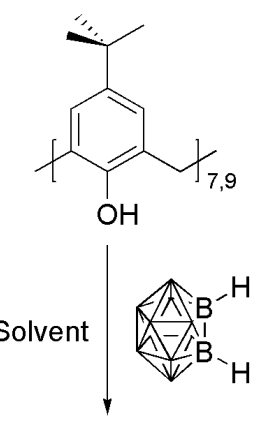

1: $2\left(p-\mathrm{Bu}^{\mathrm{t}}\right.$-calix[9]arene).7(o-carborane).2(cyclohexane).5( $\left.\mathrm{H}_{2} \mathrm{O}\right)$

2: $p$-But-calix [7] arene. $3 \%$ (toluene)

3: $p$-But-calix[7]arene.7(o-caborane).2(toluene).2(benzene)

Fig. 1 General procedure for the preparation of complexes 1-3.

\section{Results and Discussion}

All complexes were prepared by slow evaporation with 60 crystals suitable for single-crystal diffraction studies forming over 2-5 days. Complex 1 was prepared from a solution of $p$ $\mathrm{Bu}^{\mathrm{t}}$-calix[9]arene $(10 \mathrm{mg} / \mathrm{mL})$ and $o$-carborane $(5 \mathrm{mg} / \mathrm{mL})$ in a 1:1 mixture of dichloromethane and hexane. Complex 2 was prepared from a solution of $p$-Bu-calix[7] arene $(100 \mathrm{mg} / \mathrm{mL})$ 65 in toluene, and complex 3 was prepared from a solution of $p$ $\mathrm{Bu}^{\mathrm{t}}$-calix[7]arene $(150 \mathrm{mg} / \mathrm{mL})$ and $o$-carborane $(150 \mathrm{mg} / \mathrm{mL})$ in toluene. It is noteworthy that minor impurities in the solvents used, cyclohexane in hexane and benzene in toluene, are selectively taken up by the calixarene presumably due to 70 size specific inclusion in otherwise voids in the continuous structure.

\section{Crystal Structures}

Complex 1 , crystallizes in the monoclinic space group $P 2_{1} / m$ (No. 11), $Z=1$, with the asymmetric unit comprised of one 75 calix[9]arene molecule, one and a half $o$-carborane molecules, and half a $\mathrm{H}_{2} \mathrm{O}$ molecule, all located on a mirror plane and one $o$-carborane molecule, half a cyclohexane molecule and four disordered quarter occupancy water molecules in general positions. The calix[9]arene molecules possess cyclic 
intramolecular $\mathrm{H}$-bonding with $\mathrm{O} \cdots \mathrm{O}$ distances for adjacant phenolic groups ranging from 2.654(6) to 2.722(7) A. This hydrogen bonding coupled with interplay with included molecules and crystal packing forces predertimines the 5 conformation of the molecules, Fig. 2. Not surprisingly the conformations are distinctly different to those in the aforementioned metal complexes of the calixarene, where the binding of the calixarenes can predetermine the conformation of the calixarene. ${ }^{5}$ The spatial arrangement of the 10 calix[9]arene in complex $\mathbf{1}$ can be presented as a combination of three sequential trimeric substructures creating clefts, rings $4,5,6$, rings $6,7,8$ and rings $8,9,1$. The outer two ring groupings are linked by a tetrameric substructure, rings 1,2,3,4, which has two clefts, Fig. 2. All phenoxy oxygen 15 atoms of the calixarene are directed to the center of gravity of the macrocycle, Fig. 2.

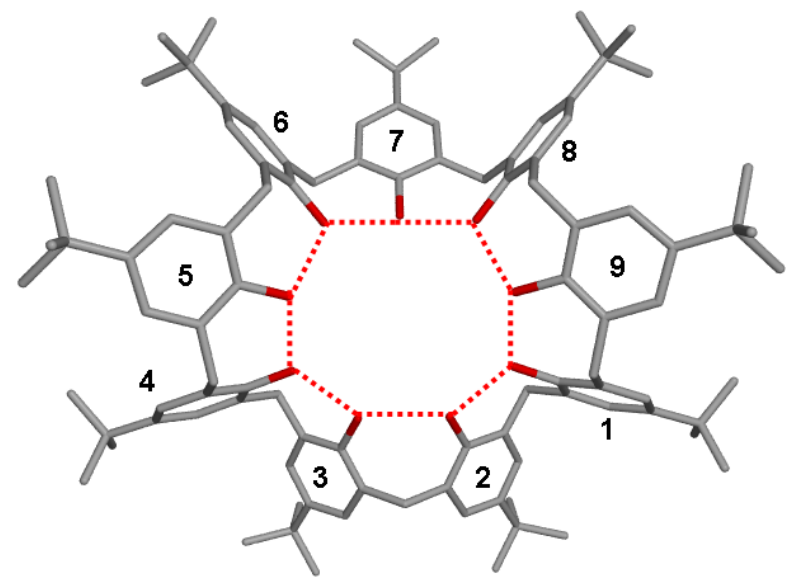

Fig. 2 General view of the $p$ - $\mathrm{Bu}^{\mathrm{t}}$-calix[9]arene molecule in complex $\mathbf{1}$, 20 down the $\left(\begin{array}{lll}1 & 0 & 0\end{array}\right)$ projection, with disorder for some $\mathrm{Bu}^{\mathrm{t}}$ groups, and $\mathrm{H}$ atoms omitted for clarity. Cyclic intramolecular H-bonding depicted by dashed red lines.

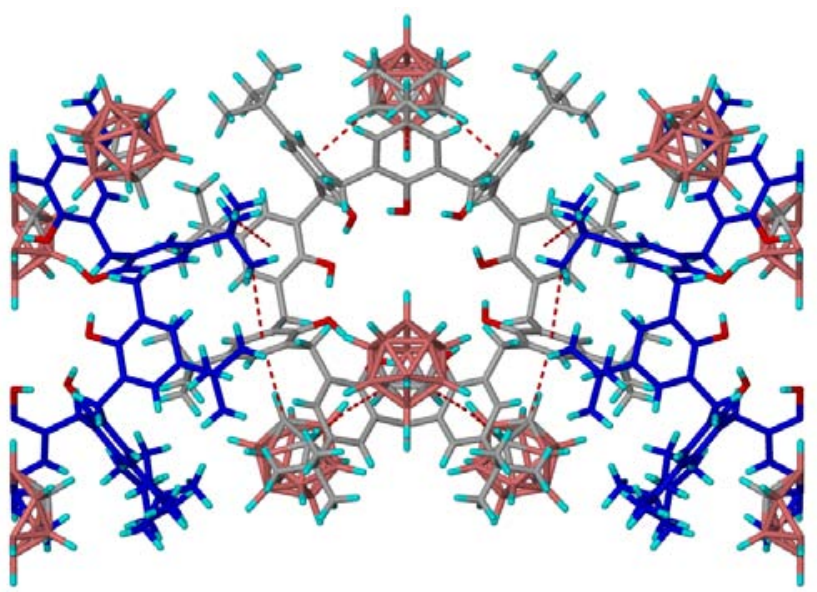

Fig. 3 Fragment of the crystal packing of complex 1 projected down the $25\left(\begin{array}{lll}1 & 0 & 0\end{array}\right)$ projection, showing the $\mathrm{C}-\mathrm{H} \cdots \pi$ interactions of the $o$-carborane molecules and neighbouring calixarenes in blue.

One $o$-carborane molecule is located inside the cleft of the central trimeric substructure (rings $6,7,8$ ) and the other $o$ carborane molecules are located inside the clefts of the
30 tetrameric substructure, Fig. 3. The shortest distances from the carbon atoms of the carboranes to the centres of neighbouring aromatic rings are in the range of $3.35-3.56 \AA$, which are consitent with $\mathrm{CH} \cdots \pi$ interactions. $^{9}$

The two remaining trimeric substructures (rings 4,5,6 and $358,9,1$ ) are occupied by $\mathrm{Bu}^{\mathrm{t}}$-moieties from adjacant calixarenes, with the shortest $\mathrm{CH} \cdots \pi$ contact at $3 . \AA 8$ for the carbon to ring centroid, Fig.3. The solvent molecules (water and adventitious cyclohexane) fill up the interstitial space.

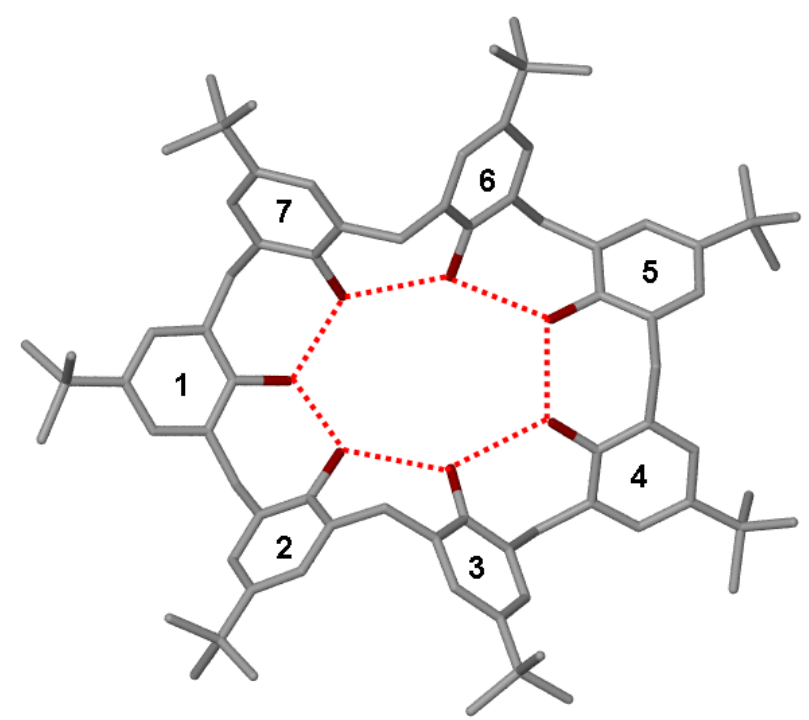

40 Fig. 4 Projection of one of the $p$-But-calix[7]arene molecules in 2 showing the trimeric substructure (rings $1,2,7$ ) and tetrameric substructure (rings 3-6), with disorder and $\mathrm{H}$-atoms omitted for clarity. Cyclic intramolecular H-bonding depicted by dashed red lines.

45 Complex 2, crystallizes in the triclinic space group $P-1$, $\mathrm{Z}=4$, with the asymmetric unit comprised of two calix[7]arene molecules and seven toluene molecules with minor disorder of the toluene molecules and $\mathrm{Bu}^{\text {t}}$-groups of one of the calix[7]arene molecules. The conformation of the calixarenes 50 are the same, and have close to m-symmetry, with the mirror plane running through ring 1, Fig. 4. The calix[7]arene molecules have the same conformation and can be considered as a combination of 1 trimeric unit (rings 1,2,7) and a tetrameric (rings 3-6), Fig. 4, which have commonality with 55 components in the structre of $\mathbf{1}$. Both calix[7]arene molecules have pseudo-mirror symmetry with the plane passing through the middle of the central ring of the trimeric substructure (ring 1) and the central methylene bridge of the tetrameric substructure (rings 4 and 5). The hydroxyl groups form a 60 strong intramolecular cyclic $\mathrm{H}$-bonding system with $\mathrm{O} \cdots \mathrm{O}$ distances $2.590(3)-2.751(3) \AA$. Symmetry extended pairs of calix[7]arene molecules form corrugated bi-layer sheets with the toluene molecules between and inside the bi-layers.

Computational analysis of the conformational isomerism of 65 calix[7]arenes by Shinkai et al. gave the present conformation of $p$ - $\mathrm{Bu}^{\mathrm{t}}$-calix[7]arene as the $19^{\text {th }}$ most stable structure. ${ }^{10}$ This is the same conformation as seen in either the $p$-Etcalix[7]arene/toluene complex ${ }^{11}$ or the p-Benzylcalix[7]arene/chlorform compelx ${ }^{12}$ and differs from the 
conformation seen in a $p$-But-calix[7]arene/pyridine complex which adopts the most stable structure. ${ }^{13}$ The energy difference between the two conformations is calculated to be $5.4 \mathrm{kcal} \mathrm{mol}^{-1},{ }^{10}$ and is due to inversion of two aromatic rings 5 (rings 4 and 5) in the flexible calix[7]arene ring system.

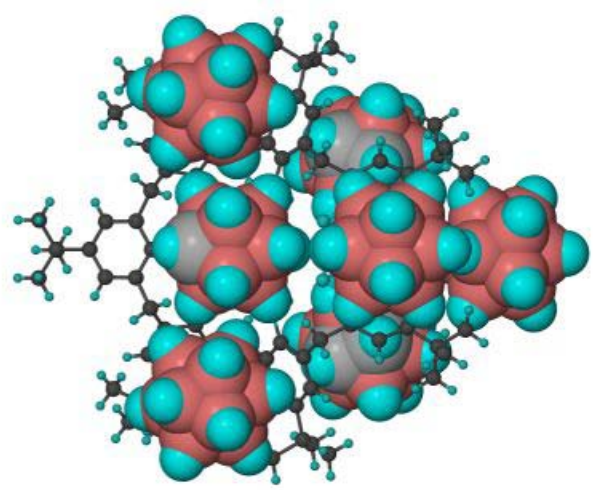

Fig. 5 Closest $p$-Bu-Calix[7]arene/o-carborane environment in complex 3 with space filling for the $o$-carborane molecules. The toluene and benzene 10 solvent molecules are omitted for clarity.

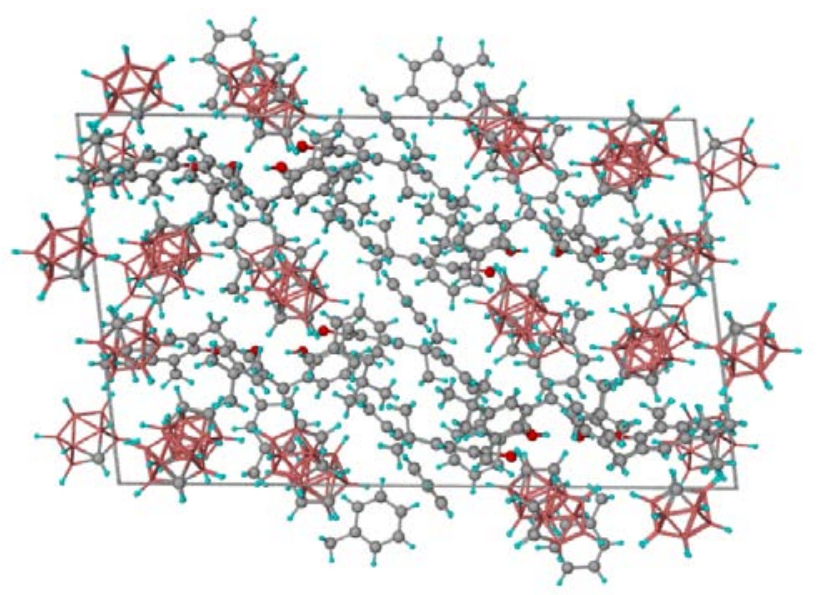

Fig. 6 Extended packing of complex 3 down the $a$-axis

Complex 3 crystallizes in the monoclinic space group $C 2 / m, Z=4$, with the asymmetric unit comprised of one 15 calix[7]arene molecule, three carborane molecules (two disordered) and two toluene molecules (one disordered) located on a crystallographic mirror plane and one benzene molecule dislocated from a mirror plane; one benzene molecule at the center of symmetry and two $o$-carborane 20 molecules in general positions.

The conformation of the calix[7]arene molecule is very similar to the one described for complex 2, differing only by the local molecular pseudo-mirror plane of the calix[7]arene now in coincidence with the crystallographic $m$ plane. The 25 hydroxyl groups form a strong intramolecular cyclic $\mathrm{H}$ bonding system with $\mathrm{O} \cdots \mathrm{O}$ distances $2.535(3)-2.698(4) \AA$.

The $o$-carborane molecule sited on the mirror plane above the central cleft of the tetrameric structure has two different orientations, Fig. 5. One is in coincidence with its $m$ so symmetry where the $\mathrm{C}-\mathrm{C}$ bond is perpendicular to the mirror plane and the associated hydrogen atoms are aligned almost to the middle of the central rings of the tetrameric structure with a carbon-ring centroid distance of $3.42 \AA$ which is consistent with a $\mathrm{C}-\mathrm{H} \cdots \pi$ interaction. The half occupancy $o$-carborane 35 molecules in this position are dislocated from a mirror plane and have been refined with constraints to its idealized form breaking the crystal symmetry.

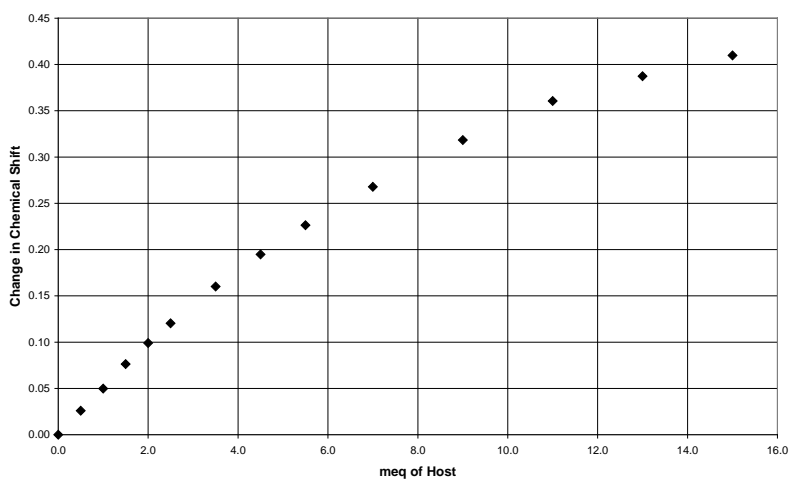

Fig. 7. NMR titration curve of the complexation of $p$ - $\mathrm{Bu}^{\mathrm{t}}$-calix[7]arene 40 with $o$-carborane giving an association constant of $5.0 \pm 0.6 \mathrm{M}^{-1}\left(\mathrm{R}^{2}=\right.$ 0.9995).

The second disordered $o$-carborane molecule is exo to the calixarene and is also located on a mirror plane, being disordered between two positions with one orientation having 45 the $\mathrm{C}-\mathrm{C}$ bond perpendicular to the mirror plane and the second with the $\mathrm{C}-\mathrm{C}$ bond in the plane, Fig. 5 . The third $o$-carborane molecule which is not disordered is on a mirror plane which is located above the oxygen network, Fig. 5. Its C-C bond is on the mirror plane and one of the carbons possibly involved in ${ }_{50} \mathrm{C}-\mathrm{H} \cdots \mathrm{O}$ H-bonding with the $\mathrm{C} \cdots \mathrm{O}$ distance at $3.004 \AA$. The final two $o$-carborane molecules are on general positions and located inside clefts between the trimeric and tetrameric structures of the calix[7]arene molecule with $\mathrm{H}$-bonds directed towards the centers of opposite aromatic rings with carbon 55 ring centroid distances, $3.41-3.51 \AA$. These are consistent with $\mathrm{C}-\mathrm{H} \cdots \pi$ interactions, Fig. 5. The extended packing is shown in Fig. 6.

\section{IR Studies}

60 The IR spectra of complexes $\mathbf{1}$ and $\mathbf{3}$ show a clear shift in $\mathrm{v}_{\mathrm{C}-\mathrm{H}}$ for $o$-carborane, which is indicative of the involvement of $O$ carborane in non-classical hydrogen bonding, ${ }^{9}$ especially given the absence of $\mathrm{H}$-bonding between the carborane molecules and $\mathrm{OH}$ groups in complexes $\mathbf{1}$ and $\mathbf{3}$. The shift in $65 \mathrm{v}_{\mathrm{C}-\mathrm{H}}$ for complexes $\mathbf{1}$ and $\mathbf{3}$ relative to uncomplexed $\mathrm{O}$ carborane are -13.5 and $-14.5 \mathrm{~cm}^{-1}$ respectively. There is no clear indication of any shift in the $v_{\mathrm{B}-\mathrm{H}}$ of $o$-carborane which is in contrast to the observed shift in the complexes of $p-\mathrm{Bu}^{\mathrm{t}}-$ calix[5]arene with $o$-carborane where the snug fit of $o$ 70 carborane in the cavity is accompanied by sterically directed $\mathrm{C}-\mathrm{H} \cdots \pi$ and $\mathrm{B}-\mathrm{H} \cdots \pi$ interactions. $^{6 \mathrm{~b}}$

\section{NMR Studies}

Solution phase studies on the complexation of $p-\mathrm{Bu}^{\mathrm{t}}$ 75 calix[7]arene with $o$-carborane gave an association constant of 
$5.0 \pm 0.6 \mathrm{M}^{-1}\left(\mathrm{R}^{2}=0.9995\right)$, Fig. 7. This is in good agreement with the association constants obtained from complexation studies of $p$ - $\mathrm{Bu}^{\mathrm{t}}$-calix[5]arene with $o$ - and $m$-carborane, 3.8 $6.4 \mathrm{M}^{-1}$, ${ }^{6}$ but the nature of the $1: 1$ complex is ill defined. It 5 was not possible to perform NMR titrations on $p$ - $\mathrm{Bu}^{\mathrm{t}}-$ calix[9]arene due to its limited solubility.

\section{Conclusions}

The inclusion chemistry of uneven higher ordered calix[7,9]arenes has been develped for the globular $o$ 10 carborane molecule. Whilst the calixarenes are not organised in a way to optimise the binding of one or more carboranes in a well defined single cavity of the calixarenes, the results are without precedent. This may not be the case for other higher calixarenes (odd and also even numbers of phenolic groups) 15 and clearly warrants investigation. The findings are likely to translate to designing therapeutic agents based on boron neutron-capture when using the water soluble calix[7,9]arene analogues in place of the hydrophobic calixarenes herein, and this is an area we are currently pursuing.

\section{Experimental}

\section{General}

All solvents were purchased from commercial suppliers and used without further purification. $o$-Carborane was purchased 25 from Katchem Ltd. and used without further purification. p$\mathrm{Bu}^{\mathrm{t}}$-calix[7] arene was prepared as described previously in the literature with $p$ - $\mathrm{Bu}^{\mathrm{t}}$-calix[9]arene isolated from the same reaction mixture. ${ }^{14}$

\section{NMR Studies}

All spectra were run on a Bruker $500 \mathrm{MHz}$ spectrometer using $99.8 \%$ chloroform- $\mathrm{d}_{1}, 99.5 \%$ benzene- $\mathrm{d}_{6}$ or $99.5 \%$ toluene- $\mathrm{d}_{8}$ (CIL). In benzene- $\mathrm{d}_{6}$ and toluene- $\mathrm{d}_{8}$ no binding of $o$-carborane was evident presumably due to the solvent having more 35 favorable $\mathrm{C}-\mathrm{H} \cdots \pi$ interactions with the walls of the calixarene than $o$-carborane. Chloroform- $\mathrm{d}_{1}$ was chosen over dichloromethane- $\mathrm{d}_{2}$ as it is more readily available and will show similar $\mathrm{C}-\mathrm{H} \cdots \pi$ interactions with the calixarene cavity. However, no data could be collected for the calixarene signals

40 with only concentration induced shifts were observed. $p-\mathrm{Bu}^{\mathrm{t}}$ calix[7]arene is highly soluble in chloroform and aromatic solvents whilst $p$-But-calix[9]arene has limited solubility in chloroform but reasonable solubility in aromatic solvents. Thus it was not possible to perform NMR titrations on $p$ - $\mathrm{Bu}^{\mathrm{t}}$ 45 calix[9]arene.

A $4 \mathrm{mM}$ solution of guest was prepared in $\mathrm{CDCl}_{3}$ and 800 $\mu \mathrm{L}$ was added to a NMR tube fitted with a rubber septum. The titration solution was prepared in $\mathrm{CDCl}_{3}$ and was $84 \mathrm{mM}$ with respect to the host and $4 \mathrm{mM}$ with respect to the guest to so ensure a constant guest concentration throughout the experiment. The titration solution was added via syringe in the stated quantities and ${ }^{1} \mathrm{H}\left\{{ }^{11} \mathrm{~B}\right\}$ NMR spectra were recorded. The chemical shift change for the $\mathrm{C}-\mathrm{H}$ signal of the carborane was analyzed by non-linear regression methods to determine
55 the association constant, Table 1 and Fig.7.

Guest solution: $5.769 \mathrm{mg}\left(4 \times 10^{-5} \mathrm{~mol}\right)$ of $o$-carborane in 10 $\mathrm{mL}$ of $\mathrm{CDCl}_{3}$.

Titration solution: $95.317 \mathrm{mg}\left(8.4 \times 10^{-5} \mathrm{~mol}\right)$ of $p-\mathrm{Bu}^{\mathrm{t}}-$ 60 calix[7]arene in $1 \mathrm{~mL}$ of $4 \mathrm{mM}$ guest solution.

$\mathrm{K}_{\mathrm{a}}$ for C-H signal: $5.0 \pm 0.6 \mathrm{M}^{-1}\left(\mathrm{R}^{2}=0.9995\right)$

Table 1. NMR titration results for $p$ - $\mathrm{Bu}^{\mathrm{t}}$-calix[7]arene in $\mathrm{CDCl}_{3}$.

\begin{tabular}{ccccccc}
\hline Sample & $\begin{array}{c}\mathrm{V}_{\text {Guest }} \\
{[\mu \mathrm{L}]}\end{array}$ & $\begin{array}{c}\mathrm{V}_{\text {Host }} \\
{[\mu \mathrm{L}]}\end{array}$ & $\begin{array}{c}\text { meq of } \\
\text { Host }\end{array}$ & $\begin{array}{c}\text { Host } \\
{[\mathrm{mM}]}\end{array}$ & $\begin{array}{c}1 \\
{[\mathrm{ppm}]}\end{array}$ & $\begin{array}{c}\Delta \delta 1 \\
{[\mathrm{ppm}]}\end{array}$ \\
\hline \hline 1 & 800 & 0 & 0.0 & 0.0000 & 3.5497 & 0.0000 \\
2 & 800 & 20 & 0.5 & 2.0488 & 3.5238 & 0.0259 \\
3 & 800 & 40 & 1.0 & 4.0000 & 3.4999 & 0.0498 \\
4 & 800 & 60 & 1.5 & 5.8605 & 3.4734 & 0.0763 \\
5 & 800 & 80 & 2.0 & 7.6364 & 3.4507 & 0.0990 \\
6 & 800 & 100 & 2.5 & 9.3333 & 3.4293 & 0.1204 \\
7 & 800 & 140 & 3.5 & 12.5106 & 3.3896 & 0.1601 \\
8 & 800 & 180 & 4.5 & 15.4286 & 3.3549 & 0.1948 \\
9 & 800 & 220 & 5.5 & 18.1176 & 3.3234 & 0.2263 \\
10 & 800 & 280 & 7.0 & 21.7778 & 3.2818 & 0.2679 \\
11 & 800 & 360 & 9.0 & 26.0690 & 3.2313 & 0.3184 \\
12 & 800 & 440 & 11.0 & 29.8065 & 3.1891 & 0.3606 \\
13 & 800 & 520 & 13.0 & 33.0909 & 3.1683 & 0.3874 \\
14 & 800 & 600 & 15.0 & 36.0000 & 3.1399 & 0.4098 \\
\hline
\end{tabular}

65

\section{X-ray Crystallography}

The X-ray diffracted intensities were measured from single crystals at about $100 \mathrm{~K}$ on an Oxford Diffraction Gemini-R Ultra or Xcalibur-S CCD diffractometer using 70 monochromatized Cu- $K_{\alpha}(\lambda=1.54178 \AA), 1$ and 2 , or Mo- $K_{\alpha}$ ( $\lambda=0.71073 \AA$ ), 3. Data were corrected for Lorentz and polarization effects and absorption correction applied using multiple symmetry equivalent reflections. The structures were solved by direct method and refined on $F^{2}$ using SHELX-97 75 crystallographic package ${ }^{15}$ and the X-Seed interface. ${ }^{16}$ A full matrix least-squares refinement procedure was used, minimizing $w\left(F_{\mathrm{o}}{ }^{2}-F_{\mathrm{C}}{ }^{2}\right)$, with $w=\left[\sigma^{2}\left(F_{\mathrm{o}}{ }^{2}\right)+(A P)^{2}+B P\right]^{-1}$, where $P=\left(F_{\mathrm{o}}{ }^{2}+2 F_{\mathrm{C}}{ }^{2}\right) / 3$. Agreement factors $\left(R=\Sigma|| F_{\mathrm{o}} \mid-\right.$ $\left|F_{\mathrm{c}}\right||/ \Sigma| F_{\mathrm{o}} \mid, w R 2=\left\{\Sigma\left[w\left(F_{\mathrm{o}}^{2}-F_{\mathrm{c}}{ }^{2}\right)^{2}\right] / \Sigma\left[w\left(F_{\mathrm{o}}{ }^{2}\right)^{2}\right]\right\}^{1 / 2}$ and GOF $=$ $80\left\{\Sigma\left[w\left(F_{\mathrm{o}}{ }^{2}-F_{\mathrm{C}}{ }^{2}\right)^{2}\right] /(n-p)\right\}^{1 / 2}$ are cited, where $n$ is the number of reflections and $p$ the total number of parameters refined). The positions of hydrogen atoms were calculated and their atomic parameters were constrained to the bonded atoms during the refinement. For complexes $\mathbf{1}$ and 3, all non-hydrogen atoms of 85 the non-disordered groups were refined anisotropically, while the disordered non-hydrogen atoms were refined isotropically using all reflections. For complex 2, non-hydrogen atoms of non-disordered fragments were refined anisotropically using all reflections. Crystal uniformity of each sample was checked 90 by determining unit cell dimensions on crystals from the same preparation and from different preparations.

Complex 1: $\mathrm{C}_{224} \mathrm{H}_{370} \mathrm{~B}_{70} \mathrm{O}_{23}, M=4187.90, F(000)=2248 e$, monoclinic, $P 2_{1} / m$ (No. 11 ), $Z=1, T=100(2) \mathrm{K}, a=$ ${ }_{95}$ 12.2461(9), $b=30.9771(9), c=19.4645(8) \AA, \beta=95.833(5)$ $\circ, V=7345.6(7) \AA^{3}, D_{c}=0.947 \mathrm{gcm}^{-3}, \sin \theta / \lambda_{\max }=0.5878$, 
$N($ unique $)=12710$ (merged from $47574, R_{\text {int }}=0.0845, R_{\text {sig }}=$ $0.1064), N_{\mathrm{o}}(I>2 \sigma(I))=5071, R=0.1337, w R 2=0.3489$ $(A, B=0.14,25.0)$, GOF $=1.000,\left|\Delta \rho_{\max }\right|=1.1(4)$ e $\AA^{-3}$. CCDC 685279.

${ }_{5}$ Complex 2: $\mathrm{C}_{103.25} \mathrm{H}_{128} \mathrm{O}_{7}, M=1481.06, F(000)=3214 e$, triclinic, $P-1$ (No. 2), $Z=5, T=100(2) \mathrm{K}, a=16.946(3), b=$ 18.816(2), $c=30.047(3) \AA, \alpha=95.586(9), \beta=90.174(11), \gamma$ $=108.796(12){ }^{\circ}, V=9021(2) \AA^{3}, D_{\mathrm{c}}=1.091 \mathrm{gcm}^{-3}, \sin \theta / \lambda_{\max }$ $=0.5878, N$ (unique) $=29877$ (merged from 142954, $R_{\text {int }}=$ $\left.100.0307, R_{\text {sig }}=0.0199\right), N_{\mathrm{o}}(I>2 \sigma(I))=22924, R=0.0810$, $w R 2=0.2338(A, B=0.14,8.8)$, GOF $=1.002,\left|\Delta \rho_{\max }\right|=$ $0.82(6)$ e $\AA^{-3}$. CCDC 685280.

Complex 3: $\mathrm{C}_{117} \mathrm{H}_{210} \mathrm{~B}_{70} \mathrm{O}_{7}, M=2485.55, F(000)=5272 e$, 15 monoclinic, $C 2 / m$ (No. 12$), Z=4, T=100(2) \mathrm{K}, a=$ 20.5027(3), $b=21.7961(2), c=34.1117(4) \AA, \beta=97.009(1)$ ${ }^{\circ}, V=15129.9$ (3) $\AA^{3}, D_{\mathrm{c}}=1.091 \mathrm{gcm}^{-3}, \sin \theta / \lambda_{\max }=0.5946$, $N($ unique $)=13646$ (merged from $135421, R_{\text {int }}=0.0849, R_{\text {sig }}=$ $0.0508), N_{\mathrm{o}}(I>2 \sigma(I))=8416, R=0.1050, w R 2=0.2747$ $20(A, B=0.18,38.0)$, GOF $=1.001,\left|\Delta \rho_{\max }\right|=1.05(7)$ e $\AA^{-3}$. CCDC 685281.

\section{Acknowledgements}

We thank the Australian Research Council and the University 25 of Western Australia for a SIRF award to TEC.

\section{Notes and references}

School of Biomedical, Biomolecular and Chemical Sciences, University of Western Australia, 35 Stirling Hwy, Crawley, W.A. 6009, Australia. Fax:

30 +61 (08) 6488 1005; Tel: +61 (08) 6488 3045; E-mail:

clraston@chem.uwa.edu.au

† Electronic Supplementary Information (ESI) available: For cystallographic data in CIF format, see DOI: 10.1039/b000000x/

35 1. For comprehensive reviews see (a) C. D. Gutsche in Calixarenes, Royal Society of Chemistry, Cambridge, 1989; (b) V. Böhmer, Angew. Chem. Int. Ed., 1995, 34, 713; (c) C. D. Gutsche in Calixarenes Revisted, Royal Society of Chemistry, Cambridge, 1998; (d) Calixarenes 2001, ed. Z. Asfai, V. Böhmer, J. Harrowfield and J. Vicens, Kluwer, Dordrecht, 2001.

2. (a) D. R. Stewart and C. D. Gutsche, Org. Prep. Proc. Int., 1993, 25, 137; (b) M. Martino and P. Neri, Mini-Rev. Org. Chem., 2004, 1, 219.

3. D. R. Stewart and C. D. Gutsche, J. Am. Chem. Soc., 1999, 121, $45 \quad 4136$

4. S. P. Bew and S. V. Sharma, Chem. Commun., 2007, 975.

5. (a) S. Fleming, C. D. Gutsche, J. M. Harrowfield, M. I. Ogden, B. W. Skelton, D. F. Stewaard and A. H. White, Dalton Trans., 2003, 3319; (b) X. Delaigue, C. D. Gutsche, J. M. Harrowfield, M. I. Ogden, B. W. Skelton, D. F. Stewart and A. H. White, J. Supramol. Chem., 2004, 16, 603.

6. (a) M. J. Hardie and C. L. Raston, Eur. J. Inorg. Chem., 1999, 195200; (b) T. E. Clark, M. Makha, C. L. Raston and A. N. Sobolev, Dalton Trans., 2006, 5449.

55 7. (a) R. J. Blanch, M. Williams, G. D. Fallon, M. G. Gardiner, R. Kaddour and C. L. Raston, Angew. Chem. Int. Ed. Engl., 1997, 36, 504; (b) M. J. Hardie, C. L. Raston and B. Wells, Chem. Eur. J., 2000, 6, 3293.

8. M. Makha, C. L. Raston, A. N. Sobolev, L. Barbour and P. Turner,
9. M. J. Hardie, P. D. Godfrey and C. L. Raston, Chem. Eur. J., 1999, 5, 1828.

10. T. Harada and S. Shinkai, J. Chem. Soc. Perkin Trans. 2, 1995, 2231.

11. M. Perrin, S. Lecoco and Z. Asfari, C. R. Acad. Sci., Ser. 2, 1990, $65 \quad 310,515$.

12. J. L. Atwood, M. J. Hardie, C. L. Raston and C. A. Sandoval, Org. Lett., 1999, 1, 1523.

13. G. D. Andreetti, F. Ugozzoli, Y. Nakamoto and S. Ishida, J. Incl. Phenom., 1991, 10, 241.

70 14. M. A. Markowitz, V. Janout, D. G. Castner and S. L. Regen, J. Am. Chem. Soc., 1989, 111, 8192.

15. (a) G. M. Sheldrick, SHELXS 97: Program for Crystal Structure Solution; University of Göttingen, Göttingen, 1997. (b) G. M. Sheldrick, SHELXL 97, Program for Crystal Structure Refinement;

75 University of Göttingen, Göttingen 1997.

16. L. J. Barbour, J. Supramol. Chem., 2001, 1, 189. 